\title{
"PROYECTOS DE LITERATURA" DE AGRIPINA MONTES DEL VALLE: UNA AUTORREFLEXIÓN SOBRE LA ESCRITURA FEMENINA DE LOS AÑOS 60 DEL SIGLO XIX EN LA PROVINCIA COLOMBIANA ${ }^{1}$
}

\author{
Adriana Villegas Botero ${ }^{2}$
}

"Proyectos de Literatura" de Agripina Montes del Valle: una autorreflexión sobre la escritura femenina de los años 60 del siglo XIX en la provincia colombiana.

Resumen: Agripina Montes del Valle publicó "Proyectos de literatura" en 1868. El análisis de este texto autorreferencial y su proceso de circulación ${ }^{3}$, identifica tópicos sobre la escritura femenina en Colombia de finales del siglo XIX, a partir de elementos de contexto sobre la autora, el concepto de habitación propia (Woolf 1929), su visión sobre la otredad, el eurocentrismo (Quijano 2000), y el rol de la prensa en la difusión de obras femeninas.

Palabras clave: mujeres escritoras del siglo XIX, literatura colombiana, literatura latinoamericana, estudios literarios del siglo XIX.

"Literature Projects" of Agripina Montes del Valle: a Reflection on Female Writing on the 1860s in the Colombian Province.

Abstract: Agripina Montes del Valle published "Literature Projects" in 1868. The analysis of this self-referential text and its circulation process identifies clichés about female writing in Colombia at the end of the 19th century, based on context elements about the author, the concept of room of one's own (Woolf 1929), her vision on otherness, Eurocentrism (Quijano, 2000), and the role of the press in the circulation of female works.

Key words: 19th century female writers, Colombian literature, Latin American literature, 19th Century Literary Studies.

\section{Agripina Montes del Valle: algunas referencias sobre su época y su entorno}

Agripina Montes del Valle es una poeta modernista, cuyo nombre suele mencionarse al referir escritoras colombianas del siglo XIX, al lado de sus antecesoras bogotanas Soledad Acosta de Samper, Pía Rigán y Josefa Acevedo de Gómez.

\footnotetext{
${ }^{1}$ Fecha de recepción: 07/05/2019.

Fecha de aceptación: 05/03/2020.

2 Docente de la Escuela de Comunicación Social y Periodismo de la Universidad de Manizales, Colombia; $\triangle$ avillegas@umanizales.edu.co.

${ }^{3}$ El análisis sobre la recepción de "Proyectos de literatura", que según Mary Luz Botero (2015: 26) generó polémica y motivó cartas de rechazo, excede los alcances de este artículo.
} 
Nació en 1844 en Salamina, municipio caldense que en ese entonces era la capital de la Provincia del Sur del Estado Soberano de Antioquia y tenía más de 4.000 habitantes (Cuesta 2014: 122). Para la época de su nacimiento y en los años de su infancia estaba en pleno desarrollo en esa región el proceso conocido como Colonización Antioqueña, que extendió la frontera agrícola hacia el sur de Sonsón: "Casi 100 poblaciones nuevas surgen en este proceso, que son habitadas por antioqueños y atraen a otra gente vecina. Será el café el sustento económico que convertirá en exitosa y de gran impacto esta colonización” (Hoyos 2015: 17).

Hija de un juez parroquial oriundo de El Peñol, Antioquia, Agripina Montes pasó algunos años de su infancia en ese municipio, así como en los recién fundados Salamina y Manizales, donde aprendió a leer y escribir. En 1854 fue enviada como interna al Colegio de la Merced ${ }^{4}$, en Bogotá, que había sido creado por el gobierno en 1832 para empezar a ofrecer educación a las mujeres. El plan de estudios incluía gramática castellana y francesa, dibujo y música, entre otros. La posibilidad de acceder a educación de calidad dejó una huella en la obra de Agripina Montes: "si bien nació en un pequeño pueblo y su familia no era muy reconocida, tuvo la oportunidad de acceder a estos estudios, que le permitieron explorar el campo de las letras" (Jaramillo 2015: 1).

De su producción literaria existe evidencia de al menos 104 poemas escritos hasta su muerte en $1915^{5}$. A la edad de 20 años comenzó a publicar: entre octubre y

\footnotetext{
${ }^{4}$ Agripina Montes del Valle no solo aprendió a leer y escribir en su infancia y tuvo la oportunidad de estudiar en Bogotá, sino que además trabajó como maestra durante buena parte de su vida. En 1870 fundó en Manizales el Colegio de la Concepción donde fue pionera del método de lecciones orales, poco frecuente en esa época en Colombia, y que luego sería antecedente del Método Montessori (Cuesta, 1982:122). En 1887 regresó a vivir a Bogotá, en donde ofreció clases particulares y trabajó en algunos colegios (Añez, 1887:4). En 1887 se trasladó a Santa Marta como directora de la Escuela Normal del Departamento del Magdalena y en 1893 asumió la dirección de un colegio en La Mesa, Cundinamarca.

${ }^{5}$ La colección virtual "Escritoras Latinoamericanas del Diecinueve" del Centro de Estudios Literarios Antonio Cornejo Polar y la Universidad Estatal de California indica que entre 1864 y 1871 Agripina Montes del Valle publicó los siguientes poemas en El Mosaico: "A mi amiga: la sensible poetisa Leonor Blander" (Octubre 19 de 1864); "El 27 de noviembre. A mi señora María Josefa Mallarino de Holguín” (3 de noviembre de 1864); "Recuerdos de una tarde. A mi estimable amiga A. S. De A" (24 de noviembre de
} 
noviembre de 1864 aparecieron sus primeros tres poemas en El Mosaico $^{6}$. Tres meses después, en febrero de 1865 , contrajo matrimonio con el poeta y periodista Miguel María del Valle Lince y se radicó en Manizales. En sus primeros años de matrimonio sólo circuló un nuevo poema suyo: “Recuerdos”, publicado en 1868 en el recién fundado El hogar, periódico dedicado al bello sexo. En 1871 escribió otros tres poemas en El Mosaico, en 1872 aparecieron otros seis en esa misma revista.; entre 1878 y 1879 publicó 12 en La Mujer y en 1883 circularía su libro Poesías de Agripina Montes del Valle, con 73 poemas.

1864); "Silva" (24 de septiembre de 1871); "Últimos instantes de Magdalena" (22 de octubre de 1871); "Silva a la muerte" (7 de enero de 1872); "La ausencia" (30 de abril de 1872); "Silva" (21 de mayo de 1872), y "Silva. En la muerte de mi hijo. A mi querida hermana la señorita Vicenta del Valle" (28 de mayo de 1872). Además publicó el poema "Recuerdos" (2 de mayo de 1868) en El hogar, periódico dedicado al bello sexo, publicación fundada en Bogotá por Nicolás Pontón, que circuló entre 1868 y 1870.

A estos 10 poemas se suma "A la América del Sur" que no ha sido rescatado, aunque se conoce como la primera obra poética de Agripina Montes del Valle en obtener un premio internacional, al ganar en Chile la Medalla de Honor en 1872.

Entre 1878 y 1879 publicó 12 poemas en La mujer: lecturas para las familias, revista fundada en Bogotá por Soledad Acosta de Samper: "A mi señora doña Carmen de Vargas en su día” (17 de octubre de 1878; "Dios. A mi señora doña P. A de B" (18 de septiembre de 1878); "Tus ojos. A la señorita Angelina Aguilar Toscano" (5 de noviembre de 1878); "Memorias de la guerra. A mi señora y amiga doña Isidora Liths" (21 de febrero de 1879); "Charada" (21 de febrero de 1879); "La vida!" (5 de mayo de 1879); "Canción” (15 de marzo de 1879); "A la señorita Rosa Franco Acosta” (20 de abril de 1879); "Un recuerdo de cariñosa amistad en la muerte de su querida madre, a la señora doña Emilia Otálora" (5 de junio de 1879); "La azucena y la rosa" (5 de julio de 1879); "Apólogo" (1 de octubre de 1879) y "La vida de las rosas. A la señorita Rosa Vargas en el día de su santo" (15 de diciembre de 1879).

En 1883 apareció su libro Poesías de Agripina Montes del Valle, con el prólogo "Las Sacerdotizas", de Rafael Pombo, que recogió 73 poemas de su autoría, uno de los cuales uno ya había aparecido en $E l$ Mosaico y otro en La mujer. Ese mismo año en el libro Romancero colombiano: homenaje de Colombia al Libertador Simón Bolívar fue incluido su poema "Bolívar". En 1887 en Parnaso Colombiano, Tomo II, Julio Añez incluye otros seis poemas suyos, tres de ellos inéditos. Colombia ilustrada le publicó "A Fernández Madrid en su centenario" en 1889 y “A un turpial goajiro" en 1890. La Revista Gris, de Max Grillo, publicó en 1894 "Eterno Amor".

Sólo en el año 2000 su obra fue nuevamente editada en forma de libro. El título Dos libros en uno, compilado por Jaime Bedoya Martínez incluye 75 poemas, de los cuales 4 no aparecen el volumen de 1883: "A Cristo sacramentado", "A Julio Arboleda", "Al Tequendama" y "Policarpa Salavarrieta". Por su parte, hay dos poemas del libro Poesías de Agripina Montes del Valle que no están en el libro de Jaime Bedoya: "A mi hija María” y "Al pensamiento".

En 2015 Hoyos Editores publicó el libro Contrapunto, un volumen que incluye poemas de Agripina Montes del Valle y de la poeta salamineña Martha Patricia Meza Giraldo. Este libro trae 29 poemas de Agripina Montes, de los cuales cuatro no aparecen en los dos libros mencionados: "A la muerte de Elvira Silva", "El último pijao", "Eterno amor" (publicado originalmente en Revista Gris) y "Bolívar", que también aparece completo y con análisis en el tomo I de Poesía colombiana del Siglo XX escrita por mujeres, de Guiomar Cuesta Escobar y Alfredo Ocampo Zamorano (2013).

${ }^{6}$ En el numeral 4 de este artículo se abordarán algunos detalles sobre las publicaciones periódicas $E l$ Mosaico, La Mujer, El Hogar y El Oasis. 


\section{El tema central: Agripina Montes del Valle y la falta de una habitación propia}

Agripina Montes del Valle fue una escritora prolífica que publicó un único poema durante sus primeros seis años de matrimonio. ¿Por qué? La clave de la respuesta está en "Proyectos de literatura", un artículo personal de 2.144 palabras que apareció entre las páginas 314 y 316 del periódico El Oasis de Medellín el 3 de octubre de 1968, firmado bajo el seudónimo de Porcia. Se trata de un artículo que no ha sido reimpreso. Una copia se encuentra disponible para consulta en la sala de libros raros y manuscritos del Banco de la República en Bogotá.

En "Proyectos de literatura" la autora explica que "al fin a fuerza de tanto sentir, es preciso que escriba" (1868: 314), pero esta necesidad se ve truncada por sus ocupaciones domésticas. Por eso en su texto, con humor y rica descripción de anécdotas íntimas familiares, señala que "la literatura, ese sueño de la mujer espiritual y sensible, no puede realizarse, cuando ella ha contraído deberes tan sagrados como los del hogar" (1868: 314). Adicionalmente cita a José María Vergara y Vergara, para explicar las diferencias de género a la hora de escribir:

ha dicho muy bien al decir que si el hombre de negocios que cultiva su imaginación hace un milagro, la mujer hace tres; y él tiene razón porque las "mujeres casadas sacrifican a las musas; pero al pie de las cunas de sus hijos y después de haber atizado la llama en el hogar cumpliendo con los deberes de esposas y madres cristianas. (1868: 314$)$

"Proyectos de literatura" es un artículo de prensa en el que Agripina Montes del Valle describe las dificultades que implica para una mujer como ella poder concluir una producción escrita. Una mujer como ella significa una mujer joven que vive en una provincia católica y conservadora en el último tercio del siglo XIX, casada, a cargo de 
tres niños pequeños y de la administración de un hogar, trabajo que implica coordinar la labor de "las criadas", como ella las denomina. Esta carga laboral afecta sus posibilidades de dedicarse a la escritura. En su artículo refiere que empezó a escribir el viernes un texto titulado "La noche" pero los gritos y el bullicio de los niños le impidieron continuar su labor. El sábado tampoco pudo hacerlo porque era una noche fría, sin luna ni luz y cuando iba a levantarse otra vez "un terceto de gritos" puso fin a su impulso de escritura. El domingo el desánimo vino por cuenta de su esposo, quien le dijo que en El Oasis ya habían publicado un artículo de Selgas titulado "La Noche”. Al día siguiente intentó retomar la escritura "pero era lunes y la casa estaba en un desorden espantoso" (1868: 315). En la noche logró por fin avanzar en un artículo que tituló "El hogar", pero el martes, cuando se disponía a "poner en limpio el borrador de "Mi hogar"' (1868: 315) se encontró con que el papel estaba lleno de tinta y arenilla porque los niños habían estado jugando en el salón: "no solo me han roto mis demás manuscritos sino que a éste le dieron baño de tinta" (1868: 316). Lo ocurrido lo lleva a afirmar que "en esta tierra las mujeres casadas no seremos nunca literatas" (1868: 316). El artículo concluye con la siguiente explicación: "Es por esto, mi piadoso lector; que no ha visto la luz pública mi artículo; pues no salió vivo del escritorio. Allí mismo murió a fuerza de baños de tinta; y es por eso que al referirte lo que me ha pasado he llamado esto "Proyectos de literatura"" (1868: 316).

La culminación del artículo y su publicación representan una aparente contradicción entre lo enunciado y el documento mismo: la autora refiere que el rol femenino que ocupa en el hogar le impide escribir, pero lo expresa por escrito, es decir: sí puede escribir. Por ello es importante su énfasis al señalar que su artículo es un proyecto de literatura, es decir, no es literatura. Se trata de un producto que dista de la intención inicial que la autora tenía. La diferencia entre la idea y el resultado se explica 
por las vicisitudes que la escritora afronta en su hogar, que le impiden avanzar en su escrito.

"Proyectos de literatura" es una producción autorreferencial que describe el proceso de producción de un escrito y el esfuerzo que acarrea esa labor de escritura. La autora no señala dificultades frente a la hoja en blanco, el lenguaje o la búsqueda de las palabras precisas. Tampoco aborda dudas sobre el enfoque, el tono o el tema. Al compararse con otros escritores, todos hombres radicados en Bogotá, advierte que puede faltarle calidad literaria ${ }^{7}$, pero se justifica diciendo que su obra nace de su experiencia sensible:

Pues si no brilla en mí el escrito la lucidez que relejan las sonoras, fáciles y hermosas composiciones del paisano Dr. Echeverri, ni se gusta en él la cadenciosa música, que imprimen en su elegante prensa Madiedo, Samper, Vergara, Borda y Caro, si me falta en fin la luz del genio, por lo menos brillará la verdad. (1868: 314)

Más adelante la autora incluye una interpelación del hipotético lector, quien le pregunta: “¿dónde está ese artículo, que ya me tienes fastidiado con tus largas digresiones y con tu pesadísima prosa?" (1868: 315). "Proyectos de Literatura" muestra entonces a una escritora que sabe que tiene algo para decir y cómo decirlo, aunque se presente en una posición de inferioridad o subestimación frente a la calidad de su obra. La autora persiste en su necesidad de escribir pero se muestra "cansada" y "fatigada", según sus propias palabras, por las circunstancias externas que su condición femenina le imponen, y que la sitúan en desventaja frente a los escritores hombres.

\footnotetext{
${ }^{7}$ En el prólogo de su libro de poesías escribe: "no os reclamo indulgencia para mis versos pero sí el olvido para las reglas de Horacio".
} 
51 años después de que Agripina Montes del Valle describiera su desazón en "Proyectos de Literatura", la escritora británica Virginia Woolf pronunció sus célebres conferencias reunidas en el ensayo Una habitación propia (1929) en donde advierte que "una mujer debe tener dinero y una habitación propia para poder escribir" (Woolf 1929: 6):

La libertad intelectual depende de cosas materiales. La poesía depende de la libertad intelectual. Y las mujeres siempre han sido pobres, no sólo durante doscientos años, sino desde el principio de los tiempos. Las mujeres han gozado de menos libertad intelectual que los hijos de los esclavos atenienses. Las mujeres no han tenido, pues, la menor oportunidad de escribir poesía. Por eso he insistido tanto sobre el dinero y sobre el tener una habitación propia. (Woolf 1929: 77)

En su ensayo, escrito nueve años después de que las inglesas obtuvieran el derecho al voto y 49 años después de que la ley británica les permitiera a las mujeres casadas ser dueñas de sus propios bienes, Woolf concluye que estos cambios han "despertado en los hombres un extraordinario deseo de autoafirmación (que los) ha empujado a hacer resaltar su propio sexo y sus características, en las que no se habrían molestado en pensar si no les hubieran desafiado" (Woolf 1929: 71).

Este deseo de autoafirmación masculina por los cambios políticos no estaba aún presente cuando Agripina Montes escribió "Proyectos de Literatura". Las colombianas lograron esas conquistas políticas varias décadas después que las inglesas: el derecho patrimonial en 1932 y el derecho al voto en 1957 (Gaviria Gil 2015: 582). En la época de Agripina Montes del Valle estos derechos ni siquiera estaban en discusión y su circunstancia corresponde a la situación que Virginia Woolf describe para las escritoras inglesas de comienzos del siglo XIX cuando, según ella, a las mujeres no se les trataba con la indiferencia que se trataba a los escritores hombres sino con hostilidad: "El mundo no le decía a ella como les decía a ellos: "Escribe si quieres; a mí no me importa 
nada”. El mundo le decía con una risotada: “Escribir? ¿Para qué quieres tú escribir?” (Woolf 1929: 39).

Esta valoración coincide con la que el poeta Rafael Pombo presenta en Las sacerdotisas, el prólogo del libro Poesías de Agripina Montes del Valle, publicado en 1883. Pombo no centra su atención en los quehaceres domésticos que ocupan a las escritoras, sino, especialmente, en los prejuicios que la sociedad tiene sobre las obras femeninas, que se escriben con esfuerzo y cuando se publican no encuentran lectores: "Muchos otros, y quizás otras, de los que nada sepan de ella, lo cerrarán al punto, diciendo con desdén: “Ah! Versos de mujer” por leídos” (Pombo 1883: III).

En "Proyectos de Literatura" Agripina Montes del Valle no explicita un reclamo a su esposo en particular o a los hombres en general sobre la inequidad en las cargas domésticas. 1868 no es aún el tiempo para expresar ese tipo de reflexiones en una provincia católica y conservadora en Colombia. Sin embargo afirmar al comienzo de su artículo "es preciso que escriba" y, luego de todos los tropiezos hogareños sufridos concluir con una declaración como "no vuelvo nunca a escribir" evidencia una actitud reflexiva sobre las renuncias a las que las mujeres se ven obligadas por su condición de género. Agripina Montes del Valle no tiene una habitación propia pero su escritura muestra a una autora que empieza a ser consciente de que la necesita.

\section{Los subtextos sobre la otredad: género, etnia y clase social}

El tema central abordado por Agripina Montes del Valle puede considerarse en una primera lectura como revolucionario para su época, en la medida en que divulga 
entre el público una queja sobre las dificultades que entrañan los roles de madre y esposa en el ejercicio literario de una mujer. De hecho, la mera existencia de una mujer escritora en la provincia colombiana en el último tercio del siglo XIX resulta revolucionaria en sí misma: hacia 1900 la tasa de analfabetismo en el país era del 66\%, muy superior a la de Brasil, Chile, Uruguay y Argentina (Ramírez Giraldo 2018: 7) y la brecha entre hombres y mujeres era notoria: en 1850 en Colombia había 13.834 niños matriculados en escuelas públicas, frente a 1.268 niñas y en 1897 las cifras eran de 71.452 niños frente a 58.230 niñas (Dane 1975: 130). En la época en que se publicó "Proyectos de literatura" las mujeres recibían un trato de inferioridad frente a los hombres dado no solo por los estándares sociales sino por el marco normativo vigente: en la Constitución de 1863 la mujer "no era pensada como ciudadano de plenos derechos en la sociedad colombiana" (Torres Preciado 2010: 55).

Sin embargo "Proyectos de literatura" revela desde el subtexto algunas visiones de la autora sobre la otredad que tienden a reforzar ideas tradicionales de género, etnia y clase social. La profesora Ana María Agudelo Ochoa, de la Universidad de Antioquia, incluye "Proyectos de Literatura" en su artículo La reflexión decimonónica sobre la escritura de mujeres en Colombia (2011) como ejemplo de uno de los "escasos los documentos que dan cuenta de una reflexión de las escritoras decimonónicas colombianas acerca de su relación con la escritura" (Agudelo 2011: 1) y califica la actitud de Agripina Montes de "atrevida" porque junto con Pía Rigán "divulgan sus reflexiones en periódicos y revistas, publicaciones que pese a sus lineamientos ideológicos, o tal vez gracias a ellos, ofrecen espacios de creación y expresión a las mujeres" (Agudelo 2011: 1). No obstante, Agudelo considera que Josefa Acevedo, Soledad Acosta, Pía Rigán y Agripina Montes refuerzan la idea tradicional de la mujer sometida a los roles de madre y esposa: 
La corriente de escritoras surgida en dicho contexto defiende una moral marcadamente católica y el modelo femenino de "el ángel del hogar", actitud que delata una postura conservadora, fenómeno interpretado por algunos como una reacción humanista ante la fuerte oleada antirreligiosa (...) Las mismas escritoras se autoimponen límites pues temen transgredir las normas socialmente establecidas, de ahí que se oculten tras el seudónimo o el anonimato, o que emitan declaraciones plenas de subestimación hacia la propia obra. (Agudelo 2011: 1)

Una lectura similar presenta el profesor M’bare N'gom Faye, jefe del Departamento de Lengua y Literatura y Director del Programa de Estudios Africanos en Morgan State University, quien critica "Proyectos de Literatura" en su texto Representaciones de la otredad: experiencia femenina e identidad en iNegras somos! (2015) al señalar que allí Agripina Montes presenta "una experiencia femenina falsificada, contaminada y, por ende, inauténtica” (2015: 123).

En "Proyectos de literatura" Agripina Montes incluye siete veces la palabra mujer. En tres de ellas se refiere a la "mujer casada", en otra dice que "la peor parte del matrimonio la tomamos las mujeres" (1868: 314) y en otra señala que "si el hombre de negocios que cultiva su imaginación hace un milagro, la mujer hace tres" (1868: 314) Las dos referencias restantes son a "la mujer espiritual y sensible" (1868: 314) y a "la mujer abnegada". En cuanto al rol de la maternidad, en dos ocasiones incluye la expresión "pobre madre" y en otra habla de "esposas y madres cristianas" (1868: 314). En ocho ocasiones escribe "hijos" y en otras cuatro "niños" en locuciones como "libre de los hijos", "lidiar con los hijos", "mis tres hijos están pequeños", "tres niños gritando" y "tres niños casi de una misma edad son para enloquecer a cualquiera" (1868: 314). En cuanto a su esposo, se refiere a él como "mi cara mitad" (1868: 315).

Su presentación del rol femenino puede considerarse conservadora, como lo señala Agudelo, por centrarse en el rol de esposa y madre. No obstante se advierte cierta 
rebeldía en algunas de sus expresiones: "Lidiar con los hijos", "mi cara mitad" o "libre de los hijos" no son expresiones propias de la esposa y madre abnegada católica ${ }^{8}$ de su época.

Más tradicionales son sus posiciones sobre etnia y clase social. Señala el profesor Aníbal Quijano que en el proceso de Conquista de América se dio una “codificación de las diferencias entre conquistadores y conquistados en la idea de raza, es decir, una supuesta estructura biológica que ubicaba a los unos en situación natural de inferioridad respecto de los otros" (Quijano 2000: 201). Esa visión eurocéntrica que naturaliza el poder del europeo a partir de su fenotipo se devela en "Proyectos de literatura", cuando Agripina Montes del Valle escribe sobre el poeta Selgas ${ }^{9}$, quien publica un artículo con el mismo título que ella estaba trabajando: "Los ojos de Selgas deben ser azules, porque según la valiente expresión del Dr. Samper "unos ojos azules son por lo común dos miniaturas del cielo" (...) ese hombre debe tener en sus ojos la expresión y el reflejo de esos cielos que canta tan admirablemente" (1868: 315).

La única descripción de algún rasgo físico del cuerpo humano que aparece en "Proyectos de literatura" es la de los ojos del poeta Selgas, a quien la autora jamás ha visto. Resulta significativo que lo imagine de ojos azules, una característica que marca distancia frente a la fisonomía de las personas indígenas y negroa, las otras etnias que poblaron el territorio que habita la autora. Imaginar que este español tiene los ojos azules es la manera en que Agripina Montes del Valle le da corporeidad a la alta calidad literaria que ella encuentra en la obra del poeta lorquino.

\footnotetext{
${ }^{8}$ Según el teólogo Luis Guillermo Sarasa Gallego "El Dios de Agripina es firme pero lejano. Su religión austera le permitió conocerlo en su versión clásica. La razón que le permeaba le concedió establecer una relación que, aunque la llenaba de esperanza, no la desligaba del dolor" (Sarasa, 2015:9).

${ }^{9}$ Se refiere al periodista y poeta español José Selgas Carrasco, quien nació en 1822 en Lorca y murió en 1882 en Madrid. Antonio Cacua Prada indica que en El Mosaico, revista en la que Agripina Montes del Valle publicó sus primeros poemas, aparecía un aviso que decía: "La suscripción se paga inticipadamente y vale $\$ 1.20$ de ley cada trimestre. Las personas que paguen un año adelantado recibirán gratis el "Libro de las flores" de José Selgas Carrasco" (Cacua, 1982:99)
} 
Esa visión eurocéntrica también se evidencia en el lenguaje que utiliza para referirse a quienes trabajan en las labores domésticas de su casa. Las denomina “criadas" y se refiere a ellas como seres inferiores. El reclamo que hace en su artículo sobre el "cansancio" y la "fatiga" que le producen las tareas del hogar y le impiden escribir no incluye el cansancio o la fatiga que puedan sentir estas otras mujeres, que ocupan un rol subordinado: son la servidumbre, otro rezago eurocéntrico de la Conquista que marca una clara diferencia de clases sociales.

Agripina Montes señala en "Proyectos de Literatura" que cuando termina el día tiene "fatigada su alma de luchar con la estupidez de las criadas, esa cruz abominable, la peor del matrimonio" (1868: 314). Luego escribe que "las criadas del día entran a las casas a servir de señoras" (1868: 314), estableciendo con la cursiva una clara diferenciación entre la imagen que ella tiene de sí misma como "señora" y la usurpación que de ese rol puede intentar hacer una mujer que no ocupa su posición social. La visión de inferioridad se refuerza en aseveraciones como "la estupidez de una criada" (1868: 316) y "ni por más que una se mate consigue quién le sirva con voluntad y con interés por las cosas de la casa" (1868: 315). En su concepto las mujeres que trabajan en su hogar son, más que una ayuda, una carga pesada, pues son ignorantes, descuidadas y voluntariosas. La diferencia se marca también en el lenguaje culto que utiliza la autora, en contraposición al lenguaje vulgar que utiliza una de sus ayudantes, y que se puede leer en un aparte del relato:

salí a preguntarle a las criadas quién había abierto las puertas a esos genios de la destrucción. -Pues su mercé mesma, me contestó Juana, una de las criadas. Cuando mi seño Triana vino de visita a prestar un número de "Los locos" dejó sin llave la puerta y el niño grande y la niña María se entraron de rejilón y cuando yo fui ya habían derramao la tinta, y luego porque su mercé no se pusiera más brava les cerré la puerta y los dejé adentro, y cuando busté jué a sacar la visita al portón les abrí otra vez y salieron. (1868: 315$)$ 
El uso de la cursiva le sirve a la autora para marcar distancia entre ella y otras mujeres que en su visión de mundo no pueden ubicarse en situación de igualdad.

\section{La circulación del artículo: periódicos y revistas para llegar a los lectores}

A diferencia de algunas de sus contemporáneas y muchas de sus antecesoras, Agripina Montes del Valle no es una escritora de diarios íntimos o piezas personales ocultas: escribe para publicar en periódicos y revistas, es decir, busca a los esquivos y escasos lectores de los que habla Pombo en Las sacerdotizas, aunque en ocasiones oculte su identidad con un seudónimo "pues aún es problemática la relación de la mujer con la esfera pública" (Agudelo 2011: 1).

La relación de Agripina Montes del Valle con los periódicos y revistas es de doble vía: es lectora y escritora. En "Proyectos de literatura" narra: "me puse a leer los periódicos del correo que habían llegado de Bogotá” (1868: 315). Se trata de prensa que llega desde la capital porque en 1868 aún no había periódicos ni revistas en Manizales: el primer periódico de la ciudad fue El Ruiz, que empezó a circular seis años después, el 21 de septiembre de 1874, bajo la dirección de Alejandro Restrepo R. (Cacua 1982: 76). Agripina Montes del Valle fue una de sus colaboradoras.

"Proyectos de literatura" fue publicado en una revista, como buena parte de la producción literaria de Agripina Montes del Valle. Esa característica sobre la circulación de su obra es común a muchas otras escritoras latinoamericanas del siglo XIX, como lo refieren las profesoras Carolina Alzate y Betty Osorio (2017): 
Muchas escritoras empezaron su escritura en los periódicos, y algunas incluso publicaron todo su trabajo en los periódicos antes de que éste apareciera en libros (de hecho, la mayor parte de su producción nunca apareció en forma de libro). Benedict Anderson ha demostrado, de manera muy productiva, que las comunidades nacionales del siglo XIX fueron imaginadas a través de periódicos y novelas. Ambos espacios son altamente políticos, y el periodismo no fue inicialmente más abierto a las mujeres que la literatura. Aunque el periodismo es menos duradero que los libros $-\mathrm{y}$ las escritoras por lo tanto serían menos culpables de la arrogancia de entrar en ellos, siendo la arrogancia uno de los pecados que debían evitar- ellas consiguieron espacio en los periódicos como columnistas o (rara vez) editoras, e incluso fundaron sus propios medios. ${ }^{10}$ (Alzate y Osorio 2017: 14)

Esta vía de acceso a la élite cultural corresponde a la que Ángel Rama describe como "Ciudad Modernizada" dentro de la Ciudad letrada: una época en la que la lucha por disminuir el analfabetismo en distintos países de América Latina permitió que otras capas accedieran a la educación y esos nuevos lectores se convirtieran en primer lugar en compradores de periódicos y revistas, antes que de libros (Rama 1984: 66). Como lo señala el escritor Juan Carlos Acevedo al referirse a la literatura caldense del siglo XIX: “Los grupos de intelectuales, humanistas, artistas emergentes, políticos y empresarios vieron en las publicaciones seriadas una manera de visibilizar sus ideas, sus pensamientos, sus sensibilidades" (Acevedo 2016: 52).

"Proyectos de Literatura" es la única colaboración de Agripina Montes del Valle que aparece en El Oasis, periódico de Medellín que circuló los sábados, entre el 11 de enero de 1868 y el 26 de diciembre de 1869. Su editor fue Isidoro Isaza y en él colaboraron Gregorio Gutiérrez González, quien publicó allí por primera vez sus conocidos poemas "Aures" y "Memoria Científica sobre el cultivo del maíz en los climas cálidos de Antioquia"; Epifanio Mejía, Camilo Antonio Echeverri, Manuel Uribe Ángel, Demetrio Viana, Ricardo López y Pedro A. Isaza (Cacua 1982: 104).

${ }^{10}$ Traducción propia. El artículo original está en inglés. 
En "Proyectos de literatura" Agripina Montes del Valle menciona la "elegante prensa" de "Madiedo, Samper, Vergara, Borda y Caro". Se trata de José María Madiedo, José María Samper Agudelo, José María Vergara y Vergara, José Joaquín Borda y Miguel Antonio Caro, quienes coincidían en la tertulia fundada en Bogotá en 1958 por José María Vergara y Vergara y Eugenio Díaz Castro. Esta tertulia dio origen a la revista El Mosaico, en donde Agripina Montes del Valle publicó sus primeros poemas.

El Mosaico fue una revista bogotana cuya primera edición circuló el 24 de diciembre de 1858. En comparación con otras publicaciones periódicas de su tiempo tuvo larga vida, ya que estuvo vigente durante 14 años, hasta diciembre de 1872. En sus páginas escribieron también Pía Ragán, José Manuel Marroquín, Jorge Isaacs, Ricardo Carrasquilla, Felipe Pérez y Ricardo Silva, entre otros (Cacua 1982: 98).

En mayo de 1868, meses antes de la publicación de "Proyectos de literatura", Agripina Montes publicó un poema en El hogar, periódico dedicado al bello sexo, publicación bogotana dirigida por Nicolás Pontón, quien también fundó La ilustración, La Prensa y El Catolicismo. El hogar empezó a circular en enero de ese año y contó con la participación de varios de los contertulios mencionados en "Proyectos de Literatura" y que también publicaban en El Mosaico: José María Vergara, José Joaquín Borda y José María Samper, a quienes se suma Rafael Pombo (Cacua 1982: 103). “Como la mayoría de los periódicos dirigidos por Pontón, El Hogar inicia y finaliza con su carácter literario, a pesar de que en ocasiones se tocaban temas como la educación y la política, que trataban de desviar su objetivo" (Vallejo y Meneses 2012: 298).

En "Proyectos de literatura" aparece una autora de provincia que está informada sobre la obra de un poeta español (Selgas) y sobre las obras de al menos cinco escritores 
bogotanos, además de un paisano suyo a quien se refiere como "Dr. Echeverri". En el caso de Madiedo, Samper, Vergara, Borda y Caro, se trata de una relación que trasciende la mera lectura distante de sus artículos, ya que hay un constante entrecruzamiento entre las publicaciones que fundan, dirigen, editan o cuentan con la participación de estos escritores y aquéllas en las que colabora la poeta salamineña. En ninguna de las escasas biografías de Agripina Montes del Valle se explica cómo surgió la relación de la poeta con los editores de Bogotá y Medellín que la publicaron cuando aún vivía en Manizales. Lo que sí es claro es que cuando se mudó a vivir en Bogotá, en 1878, continuó una relación literaria con los escritores con quienes ya había tenido acercamientos a través de la prensa y el correo ${ }^{11}$.

\section{Consideraciones finales}

"Proyectos de literatura" es un artículo de prensa que permite identificar algunas circunstancias propias del proceso de escritura de las mujeres de la provincia colombiana en el último tercio del siglo XIX: la falta de una habitación propia y la

\footnotetext{
${ }^{11}$ Además de los mencionados periódicos y revistas, Agripina Montes colaboró con otras publicaciones periódicas. Su amistad con los hermanos Agripina Samper Agudelo (Pía Rigán) y José María Samper la acercó a la esposa de éste, Soledad Acosta de Samper. Agripina Montes publicó 12 poemas en La mujer, revista quincenal que circuló entre el 1 de septiembre de 1878 y el 15 de mayo de 1881 y que se convirtió en la primera publicación periódica en Colombia en ser dirigida por una mujer: Soledad Acosta de Samper (Cacua, 1982:110). En mayo de 1884 Acosta de Samper fundó La Familia, lecturas para el hogar, una revista mensual que circuló durante un año y también contó con la participación de Agripina Montes. Sobre el carácter de estas publicaciones de Soledad Acosta de Samper escriben las profesoras Olga Vallejo Murcia y Xiomara Meneses Cano: “...dirigido exclusivamente al público femenino, con la clara intención de mantener el orden moral de la familia a partir de lecturas que formen a la mujer en valores sociales y morales. Esto se logra en artículos como "Misión de la mujer en la época actual" y "¿En qué debe ocuparse la mujer”, ambos de Acosta" (Vallejo y Meneses 296). Además de los mencionados periódicos, también hubo colaboraciones de Agripina Montes del Valle en otras publicaciones de Medellín, como La Golondrina y La Palestra, y en las revistas bogotanas La Tarde, La Velada, El Eco Literario y en la Revista Gris, del caldense Max Grillo.
} 
concepción patriarcal del rol femenino como esposa y madre dificultan que una mujer pueda destinar tiempo para la literatura con la dedicación que quisiera.

Si bien Agripina Montes del Valle ofrece en "Proyectos de literatura" una voz "atrevida", según la califica la profesora Ana María Agudelo Ochoa, por tratarse de un testimonio que se publica en la prensa, el subtexto permite identificar lo naturalizados que están en la autora algunos rasgos del eurocentrismo cultural, los cuales se manifiestan en la concepción que la escritora construye sobre la otredad. Si bien la poeta se permite algunas quejas frente a su rol como esposa y madre, su visión étnica y de clase social es tradicionalista y conservadora, acorde a su contexto sociocultural.

El correo y el auge de los periódicos y revistas que se da en la Ciudad modernizada de la segunda mitad del siglo XIX permite que una escritora de provincia como Agripina Montes del Valle pueda empezar a publicar su obra sin necesidad de trasladarse físicamente a las ciudades que cuentan con imprentas. Así mismo los periódicos y las revistas son el vehículo mediante el cual la escritora accede a las novedades literarias de su época y establece contactos que le resultan útiles para su carrera literaria.

Agripina Montes del Valle fue la primera escritora del Gran Caldas. Su obra antecede a la de otros escritores de la región como Samuel Velásquez Botero y Max Grillo. Empezó a publicar en periódicos y revistas antes de que el General Alejandro Restrepo Restrepo le comprara una imprenta a Gregorio Gutiérrez González, con la que fundó El Ruiz, el primer periódico de Manizales. La primera tertulia literaria de Manizales data de 1873 y para ese entonces Agripina Montes ya había pertenecido a las tertulias de El Oasis, de Medellín y la que dio origen a El Mosaico, en Bogotá. Se trata entonces de una pionera en la literatura regional y de una de las figuras más interesantes 
en la literatura femenina colombiana del siglo XIX. La labor de rescate que en las últimas décadas han acometido algunos académicos, tendiente a hacer visibles las obras de las mujeres que fueron opacadas por el patriarcado cultural, ha permitido hasta ahora que en Colombia se estudie a profundidad el trabajo de Soledad Acosta de Samper. Ojalá en el futuro las investigaciones en este campo se descentralicen, para poder conocer la producción literaria de las mujeres que escribieron por fuera de la capital.

\section{Referencias bibliográficas}

Acevedo Ramos, Juan Carlos. 2016. Las letras que nos nombran. Revisión de la literatura del Viejo Caldas 1834-1966. Bogotá, Colombia: Banco de la República. http://babel.banrepcultural.org/cdm/ref/collection/p17054coll18/id/348 [07/05/ 2019].

Agudelo Ochoa, Ana María. 2011. "La reflexión decimonónica sobre la escritura de mujeres en Colombia." Ciberletras: Revista de crítica literaria y de cultura 25. http://www.lehman.cuny.edu/ciberletras/v25/agudeloochoa.html [07/05/2019].

Añez, Julio. 1887. Parnaso colombiano, Tomo 2. Bogotá: Librería ColombianaCamacho Roldán \& Tamayo. http://babel.banrepcultural.org/cdm/singleitem/ collection/p17054coll10/id/2252/rec/1 [07/05/2019].

Botero, Mary Luz. 2015. "Agripina Montes del Valle en la prensa literaria del siglo XIX. Sombras y memoria de una gran poeta". Contrapunto. Manizales: Hoyos Editores

Cacua Prada, Antonio. 1982. Historia del periodismo colombiano. Bogotá: Ediciones Sua Ltda. Segunda edición.

Cuesta Escobar, Guiomar y Ocampo Zamorano, Alfredo. 2013. Poesía colombiana del Siglo XX escrita por mujeres, Tomo I. Poetas nacidas hasta 1949. Bogotá, Colombia: Apidama Ediciones.

Cuesta Escobar, Guiomar. 2014. "Poetas colombianas del siglo XX". En otras palabras (Universidad Nacional de Colombia), 21-22: 118-128. [Bogotá, Colombia]. https://issuu.com/revistaenotraspalabras/docs/eop2122_001d28d2a7c99b/2?ff=tru e\&e $=24234456 / 34635245$ [07/05/2019]. [07/05/2019]. 
DANE. 1975. Estadísticas históricas. Talleres del Departamento Administrativo Nacional de Estadísticas Dane, Bogotá. 201 páginas. http://biblioteca.dane. gov.co/media/libros/LD_959_EJ_4.PDF [07/05/2019].

Gaviria Gil, María Virginia. 2015. "Derecho de propiedad y protección a la mujer y a la familia. Las inconsistencias del legislador colombiano". Revista de la Facultad de Derecho y Ciencias Políticas - UPB (Universidad Pontificia Bolivariana), 45 (123): 577-598. [Medellín, Colombia] http://www.scielo.org.co/pdf/rfdcp/ v45n123/v45n123a10.pdf [07/05/2019].

Hoyos Körbel, Pedro Felipe. 2015. El siglo XIX de Agripina Montes del Valle. Contrapunto. Manizales: Hoyos Editores.

Jaramillo Salazar, Laura. 2015. "Agripina Montes del Valle”. En Escritoras latinoamericanas del siglo XIX. Eladd. Colección Virtual. Centro de Estudios Antonio Cornejo Polar y Universidad Estatal de California. http://eladd.org/otrasautoras/agripina-montes-del-valle/\# [07/05/2019].

Montes del Valle, Agripina (Porcia). 1868 (octubre 3). "Proyectos de literatura". El Oasis [Medellín, Colombia]: 314-316. Impreso.

Ngom, Mbare. 2015. "Representaciones de la otredad: experiencia femenina e identidad en ¡Negras somos!”. Cuadernos de Literatura, 19 (38): 119-136. https://dialnet.unirioja.es/servlet/articulo?codigo=5228218 [07/05/2019].

Osorio, Betty y Alzate, Carolina. 2017. "Women and Writing in Spanish America from Colonial Times through the 20th Century". Oxford Research Encyclopedia of Literature: 1-32.

Pombo, Rafael. 1883. "Las sacerdotisas. Conversación a propósito del libro de la señora Montes del Valle". Poesías de Agripina Montes del Valle. Bogotá: Imprenta de Vapor de Zalamea.

Quijano, Aníbal. 2000. "Colonialidad del poder, eurocentrismo y América Latina.” La colonialidad del saber: eurocentrismo y ciencias sociales. Perspectivas Latinoamericanas. Edgardo Lander (comp.) CLACSO, Consejo Latinoamericano de Ciencias Sociales, 2000. 201-245. http://bibliotecavirtual.clacso.org.ar/ar/libros /lander/quijano.rtf [07/05/2019].

Rama, Ángel. 1984. La ciudad Letrada. Editorial Arca, Montevideo. 126 páginas.

Ramírez Giraldo, María Teresa, Meisel-Roca, Adolfo y JaramilloEcheverri, Juliana. 2018. "Más de cien años de avances en el nivel de vida: El caso de Colombia". Cuadernos He Historia Económica, 46. http://repositorio.banrep.gov.co/bitstream/handle/20.500.12134/6974/che_46.pdf? sequence $=1 \&$ isAllowed $=y[07 / 05 / 2019]$.

Sarasa Gallego, Luis Guillermo. 2015. "Prólogo: Dos mujeres, dos tiempos, dos miradas". Contrapunto. Manizales: Hoyos Editores. 
Torres Preciado, Javier Fernando. 2010. "La mujer en la segunda mitad del Siglo XIX. Una sombra presente". Goliardos, XII: http://www.bdigital.unal.edu.co/44954/1/45166-216806-1-SM.pdf [07/05/2019].

Vallejo Murcia, Olga y Meneses Cano, Xiomara. 2012. "Publicaciones seriadas de la literatura colombiana. Fuentes periódicas para el estudio histórico de la literatura colombiana. Compilación y reseña. Segunda entrega". Estudios de literatura colombiana, 31: 293-307. http://aprendeenlinea.udea.edu.co/revistas/index. php/elc/article/view/14456/12697 [07/05/2019].

Woolf, Virginia. 1929. Una habitación propia. Barcelona: Seix Barral. 